\title{
Alzheimer's disease and the genetics of neuroprotection
}

Tyler Johnson

\begin{abstract}
As the world's leading form of age-related dementia, Alzheimer's disease (AD) is a devastating neurological disorder associated with severe emotional and economic burdens. Despite years of research, the underlying mechanism behind this disease remains unclear. The current prevailing theory relies on the deposition of toxic amyloid beta ( $A \beta)$, which promotes the formation of phosphorylated tau tangles, and together these damaging changes drive the loss of neurons. Much of AD development can be attributed to genetic influences, including pathogenic variants of $\beta$-amyloid precursor protein, presenilins 1 and 2, and the presence of apolipoprotein 4. However, there are other subtle, yet significant variations within our genome that contribute to protecting us against $\mathrm{AD}$. Variants of the phospholipase $\mathrm{C} \gamma 2$ and toll-like receptor 4 genes have been associated with reduced risk of developing $\mathrm{AD}$, as well as increased longevity of patients. These neuroprotective variants can guide the development of future therapeutic interventions for $\mathrm{AD}$, as current strategies have proven lackluster.
\end{abstract}

\section{WHAT IS ALZHEIMER'S DISEASE?}

Alzheimer's disease (AD) is the world's leading form of agerelated dementia, accounting for upwards of $80 \%$ of cases. ${ }^{1} \mathrm{AD}$ is classified as a chronic major devastating neurological disorder that clinically manifests primarily as memory loss. AD symptoms progress from mild to severe and continue to accumulate; these include difficulties with language and performing daily activities, as well as behavioral disturbances, to name a few. ${ }^{2}$ These symptoms are accompanied by an overall loss of mass, or "thinning," of the brain in patients with Alzheimer's disease. ${ }^{3}$ As of 2015, Alzheimer's Disease International estimates 46.8 million people are living with age-related dementia, and that this number will effectively double within roughly 20 years. ${ }^{4}$ In addition to the emotional burden that can be placed on individuals and families affected by this disease, the economic health care burden was estimated at US $\$ 236$ billion in 2016 alone. 'With a steady increase in the aging population, these burdens will continue to grow with the increase in $\mathrm{AD}$ cases, emphasizing the dire need for dedicated research and therapeutic development.

While $\mathrm{AD}$ is one of the most well-known diseases of the mind, the underlying mechanism remains unclear. There are two common identifiable pathologies of AD: the collection of misfolded amyloid beta $(A \beta)$ protein into plaques that surround the neurons in the brain, and the formation of tau tangles within the neurons of the brain. ${ }^{1} \mathrm{~A} \beta$ plaques arise from cleavage of the protein $\beta$-amyloid precursor protein (APP), and are considered the primary drivers in the development of $\mathrm{AD} .^{5} \mathrm{~A} \beta$ plaque deposition is also thought to precede and promote tau tangle formation, which together drive downstream neuronal damage and loss., ${ }^{5,6}$ While there is a clear association between $A \beta$ plaque deposition and the formation of tau tangles leading to the neurodegenerative symptoms seen in $\mathrm{AD}$, the exact mechanism by which this occurs is still unknown. The current prevailing theory relies on $\mathrm{A} \beta$ peptides promoting the phosphorylation of tau, either by directly affecting the responsible kinase or by inducing inflammation in the brain, thereby inducing formation of tangles.?

\section{GENETIC BASIS OF ALZHEIMER'S DISEASE}

$\mathrm{AD}$ is separated into two major subdivisions based on age, late onset $\mathrm{AD}$ (>60-65 years; 95\%) and early onset $\mathrm{AD}(<60-65$ years; $5 \%) .{ }^{8}$ Between both subdivisions, genetics is estimated to contribute upwards of $70 \%$ of $\mathrm{AD}$ risk. ${ }^{9}$ The most common genetic risk factor for the development of late onset $\mathrm{AD}$ is the presence of the apolipoprotein type 4 allele (APOE e4), which increases risk 3 to 10 times over the $10-15 \%$ baseline risk in the general population. ${ }^{8-11}$ Apolipoprotein $\mathrm{E}$ (ApoE) is an essential protein in the body, responsible for the transport of dietary fats between tissues, the breakdown of cholesterol, and has been linked to the clearance of $A \beta$. The APOE e4 risk allele is associated with reduced clearance of $A \beta$, increasing the rate at which $A \beta$ plaques deposit, thereby increasing the risk for $\mathrm{AD} .{ }^{12}$

Pathogenic variants of the APP gene, as well as presenilins 1 and 2 (PSEN1 and PSEN2), are causative in the development of early onset $\mathrm{AD}{ }^{8,13}$ While each of these variants are different, they all result in increased production of the toxic $A \beta$ peptide, once again promoting $\mathrm{A} \beta$ plaque deposition and increasing risk of $\mathrm{AD}$. Despite identifying more than 30 APP variants that are associated with AD development, therapeutic targeting of this pathway has proven lackluster. ${ }^{14,15}$

\section{NEUROPROTECTIVE VARIANTS}

The majority of studies on $\mathrm{AD}$ are centred around developing therapeutics to treat a disease-causing protein, yet there are very few studies that address the protective genetic factors. This is a largely unexplored avenue to gain additional insight into the key factors contributing to disease and to highlight the most important areas to focus our therapeutic strategies. It is generally understood that the apolipoprotein type 2 allele (APOE e2) can provide a neuroprotective effect against the development of $\mathrm{AD}$, as it has been shown to clear $A \beta$ peptides more effectively than other forms of ApoE. ${ }^{17,18}$ However, there is a sacrifice that comes along with this neuroprotection, in that the normal function of ApoE type 2-clearing dietary fat-is impaired. This has linked 
APOE e2 to increased risk for type III hyperlipoproteinemia and atherosclerosis. ${ }^{19}$ Despite the protective effects it may provide, APOE e2 is relatively rare in the population; thus, other examples of neuroprotection need to be investigated. ${ }^{20}$

Recently, van der Lee and colleagues investigated the previously reported neuroprotective Pro522Arg variant within the phospholipase $\mathrm{C} \gamma 2$ (PLCG2) gene, which was first identified in 2017 by Sims and Colleagues. ${ }^{19,22}$ Considering Plcg2 is involved in the propagation of essential immune cell signals, and immune signaling has been linked to the development of $\mathrm{AD}$, it comes as no surprise that these gene variants would have implications in the development of $\mathrm{AD}^{23,24}$ van der Lee and colleagues confirmed that the Pro522Arg variant (Pro522Arg-PLCG2) was associated with reduced risk of $\mathrm{AD}$, as well as increased longevity. As mentioned, the presence of the APOE e4 allele is a major risk factor for the development of AD; however, there are select cases where the subjects are healthy. ${ }^{10}$ The authors suggest these select patients may be benefiting from this Pro522Arg-PLCG2 variant, or some other neuroprotective variant.

Another example of neuroprotection comes from the toll-like receptor 4 (TLR4), which is an essential immune receptor for the innate immune system..$^{25}$ The interplay between immune receptors and $\mathrm{AD}$ development is complicated; however, TLR4 has been previously associated with the clearance of $A \beta$ peptide, subsequently reducing risk of AD. ${ }^{26}$ Miron and colleagues took it upon themselves to investigate a newly identified Asp299Gly variant of TLR4 (Asp299Gly-TLR4), ${ }^{27}$ which was shown to be associated with diminished risk of developing the late-onset form of $\mathrm{AD} .{ }^{28}$ With a new subset of patients, they confirmed the significant association of this variant with a reduced risk of AD. In fact, this variant was found to be present in roughly half of $\mathrm{AD}$ patients, compared to control subjects. In addition, this variant form of TLR 4 was associated with increased thickness in two areas of the brain commonly affected by thinning in $\mathrm{AD}$ : the frontal lobe and the fusiform. As discussed, thinning of the cortical regions of the brain is associated with $\mathrm{AD}$ progression; thus, prevention of this feature is a clear indication of neuroprotection. ${ }^{3}$

While it is beneficial to identify these protective variants, this knowledge has little impact if we cannot understand why they are protective. When it comes to the Pro522Arg-PLCG2, the most likely explanation is that this variant of PLCG2 limits its interaction with the NLRP3 inflammasome-activation of which has been linked to a variety of neurodegenerative disorders, including $\mathrm{AD}$-thus, reducing the risk for neurodegeneration. ${ }^{29}$ As for the Asp299Gly-TLR4 variant, it was found that carriers exhibit lower levels of interleukin-1 $\beta$ (IL-1 $\beta$ ) compared to non-carriers. AD patients typically exhibit elevated levels of IL-1 $\beta$, implicating it as a causative factor for the sustained thickness in the brain and providing a neuroprotective effect for carriers. ${ }^{30}$

As with the APOE e2 example, there is a trade-off for neuroprotection in these two cases. The Pro522Arg-PLCG2 variant likely reduces its ability to activate the NLRP3 inflammasome and the Asp299Gly-TLR4 variant has been shown to reduce the response of TLR4 to its ligand, lipopolysaccharide. ${ }^{31}$ While these may be beneficial outcomes for reducing risk of $\mathrm{AD}$, these changes leave the body susceptible to bacterial infection, as these proteins are involved in essential immune signaling responses. Studying these protective variants gives us insight into the factors contributing to $\mathrm{AD}$ development, but also inform us on the costs that would come along with designing therapeutics against these alterations. When designing new drugs for treating a disease, we often do not know the off-target effects that would come along with the treatment. Whereas, if we were to design a therapy around these protective variants, we would have a sense of these off-target effects and could incorporate a remedy for those into the therapy itself. On the other hand, we would need to consider the risk versus benefit for designing these therapies if we were unable to incorporate these remedies. Seeing as our immune system is our only defense against pathogens, these changes are not small sacrifices that would need to be made to benefit from neuroprotection.

\section{CONCLUSION}

As is the cyclical nature of research, further investigations into the precise mechanism by which these variants provide a neuroprotective effect will need to be performed. While it is critical to study disease-causing alterations to design new therapeutic strategies, it is just as important to study the innate mechanisms that have arisen to protect ourselves from disease. The two examples presented in detail here centre around the involvement of inflammation in the development of $\mathrm{AD}$; however, there are other examples of neuroprotective variants against $\mathrm{AD}^{32,33}$ The discovery of these genetic alterations is sure to be joined by many more in the future, as these unique cases provide us with a new perspective to learn about the underlying mechanisms behind disease progression. Not only will they reveal essential elements to the pathways involved in AD development and risk, but they may also hold promise for developing new innovative therapeutics.

\section{REFERENCES}

1. 2016 Alzheimer's disease facts and figures. Alzheimers Dement. 2016 Apr;12(4):459-509. https://doi.org/10.1016/j.jalz.2016.03.001

2. Burns A, Iliffe S. Alzheimer's disease. BMJ. 2009;338:b158. https://doi. org/10.1136/bmj.b158

3. Singh V, Chertkow H, Lerch JP, et al. Spatial patterns of cortical thinning in mild cognitive impairment and Alzheimer's disease. Brain. 2006 Nov;129(11):2885-93. https://doi.org/10.1093/brain/awl256

4. Prince M, Wimo A, Guerchet M, et al. World Alzheimer report 2015. The global impact of dementia: an analysis of prevalence, incidence, cost and trends. London: Alzheimer's Disease International; 2015.

5. Hardy J, Selkoe DJ. The amyloid hypothesis of Alzheimer's disease: progress and problems on the road to therapeutics. Science. 2002 Jul;297(5580):353-6. https://doi.org/10.1126/science.1072994

6. Lane CA, Hardy J, Schott JM. Alzheimer's disease. Eur J Neurol. 2018 Jan;25(1):59-70. https://doi.org/10.1111/ene.13439

7. LaFerla FM. Pathways linking Abeta and tau pathologies. Biochem Soc Trans. 2010 Aug;38(4):993-5. https://doi.org/10.1042/BST0380993

8. Bird TD. Alzheimer disease overview [Internet]. In: Adam MP, Ardinger HH, Pagon RA, et al., editors. GeneReviews ${ }^{\circledR}$. Seattle (WA): University of Washington, Seattle; 1993 [cited 2020 Jan 20]. Available from: http://www.ncbi.nlm.nih.gov/books/NBK1161/ 
9. Ballard C, Gauthier S, Corbett A, et al. Alzheimer's disease. Lancet. 2011 Mar;377(9770):1019-31. https://doi.org/10.1016/S01406736(10)61349-9

10. Silva MV, Loures C de M, Alves LC, et al. Alzheimer's disease: risk factors and potentially protective measures. J Biomed Sci. 2019;26:33. https://doi.org/10.1186/s12929-019-0524-y

11. Lautenschlager NT, Cupples LA, Rao VS, et al. Risk of dementia among relatives of Alzheimer's disease patients in the MIRAGE study: what is in store for the oldest old? Neurology. 1996 Mar;46(3):641-50. https:// doi.org/10.1212/wnl.46.3.641

12. Liu C-C, Kanekiyo T, Xu H, et a;. Apolipoprotein E and Alzheimer disease: risk, mechanisms, and therapy. Nat Rev Neurol. 2013 Jan;9(2):106-18. https://doi.org/10.1038/nrneurol.2012.263

13. Bateman RJ, Aisen PS, De Strooper B, et al. Autosomal-dominant Alzheimer's disease: a review and proposal for the prevention of Alzheimer's disease. Alzheimers Res Ther. 2011 Jan;3:1. https://doi. org/10.1186/alzrt59

14. Gilman S, Koller M, Black RS, et al. Clinical effects of Abeta immunization (AN1792) in patients with AD in an interrupted trial. Neurology. 2005 May;64(9):1553-62. https://doi.org/10.1212/01. WNL.0000159740.16984.3C

15. Ikeuchi T, Dolios G, Kim S-H, et al. Familial Alzheimer disease-linked presenilin 1 variants enhance production of both Abeta 1-40 and Abeta 1-42 peptides that are only partially sensitive to a potent aspartyl protease transition state inhibitor of "gamma-secretase." J Biol Chem. 2003 Feb;278(9):7010-8. https://doi.org/10.1074/jbc.M209252200

16. Shih H-P, Zhang X, Aronov AM. Drug discovery effectiveness from the standpoint of therapeutic mechanisms and indications. Nat Rev Drug Discov. 2018 Jan;17(1):19-33. https://doi.org/10.1038/nrd.2017.194

17. Corder EH, Saunders AM, Risch NJ, et al. Protective effect of apolipoprotein E type 2 allele for late onset Alzheimer disease. Nat Genet. 1994 Jun;7(2):180-4. https://doi.org/10.1038/ng0694-180

18. Conejero-Goldberg C, Gomar JJ, Bobes-Bascaran T, et al. APOE2 enhances neuroprotection against Alzheimer's disease through multiple molecular mechanisms. Mol Psychiatry. 2014 Nov;19(11):124350. https://doi.org/10.1038/mp.2013.194

19. Mahley RW, Rall SC. Apolipoprotein E: far more than a lipid transport protein. Annu Rev Genomics Hum Genet. 2000 Sep;1:507-37. https:// doi.org/10.1146/annurev.genom.1.1.507

20. Wu L, Zhao L. ApoE2 and Alzheimer's disease: time to take a closer look. Neural Regen Res. 2016 Apr;11(3):412-3. https://doi. org/10.4103/1673-5374.179044

21. van der Lee SJ, Conway OJ, Jansen I, et al. A nonsynonymous mutation in PLCG2 reduces the risk of Alzheimer's disease, dementia with Lewy bodies and frontotemporal dementia, and increases the likelihood of longevity. Acta Neuropathol (Berl). 2019 Aug;138:237-50. https://doi. org/10.1007/s00401-019-02026-8

22. Sims R, van der Lee SJ, Naj AC, et al. Rare coding variants in PLCG2, ABI3, and TREM2 implicate microglial-mediated innate immunity in Alzheimer's disease. Nat Genet. 2017 Sep;49(9):1373-84. https://doi. org/10.1038/ng.3916

23. Koss H, Bunney TD, Behjati S, et al. Dysfunction of phospholipase $\mathrm{C} \gamma$ in immune disorders and cancer. Trends Biochem Sci. 2014 Dec;39(12):603-11. https://doi.org/10.1016/j.tibs.2014.09.004

24. McGeer PL, Rogers J, McGeer EG. Inflammation, antiinflammatory agents, and Alzheimer's disease: the last 22 years. J Alzheimers Dis. 2016 Oct;54(3):853-57. https://doi.org/10.3233/JAD-160488

25. Takeuchi O, Akira S. Pattern recognition receptors and inflammation. Cell. 2010 Mar;140(6):805-20. https://doi.org/10.1016/j.cell.2010.01.022

26. Tahara K, Kim H-D, Jin J-J, et al. Role of toll-like receptor signalling in A $\beta$ uptake and clearance. Brain J Neurol. 2006 Nov;129(11):3006-19. https://doi.org/10.1093/brain/awl249

27. Miron J, Picard C, Lafaille-Magnan M-E, et al. Association of TLR4 with Alzheimer's disease risk and presymptomatic biomarkers of inflammation. Alzheimers Dement J Alzheimers Assoc. 2019 Jul;15(7):951-60. https://doi.org/10.1016/j.jalz.2019.03.012

28. Minoretti P, Gazzaruso C, Vito CD, et al. Effect of the functional toll-like receptor 4 Asp299Gly polymorphism on susceptibility to late-onset Alzheimer's disease. Neurosci Lett. 2006 Jan;391(3):147-9. https://doi.org/10.1016/j.neulet.2005.08.047

29. Heneka MT, Kummer MP, Latz E. Innate immune activation in neurodegenerative disease. Nat Rev Immunol. 2014 Jul;14(7):463-77. https://doi.org/10.1038/nri3705

30. Brosseron F, Krauthausen M, Kummer M, et al. Body fluid cytokine levels in mild cognitive impairment and Alzheimer's disease: a comparative overview. Mol Neurobiol. 2014 Oct;50(2):534-44. https:// doi.org/10.1007/s12035-014-8657-1

31. Schmitt C, Humeny A, Becker C-M, et al. Polymorphisms of TLR4: rapid genotyping and reduced response to lipopolysaccharide of TLR4 mutant alleles. Clin Chem. 2002 Oct;48(10):1661-7. https://doi. org $/ 10.1093 /$ clinchem $/ 48.10 .1661$

32. Leduc V, De Beaumont L, Théroux L, et al. HMGCR is a genetic modifier for risk, age of onset and MCI conversion to Alzheimer's disease in a three cohorts study. Mol Psychiatry. 2015 Jul;20(7):867-73. https://doi.org/10.1038/mp.2014.81

33. Jonsson T, Atwal JK, Steinberg S, et al. A mutation in APP protects against Alzheimer's disease and age-related cognitive decline. Nature. 2012 Aug;488(7409):96-9. https://doi.org/10.1038/naturel1283 